\title{
A motivação em sala de aula: o que dizem os alunos sobre as aulas de Física do Ensino Médio?
}

\author{
Antônio Nunes de Oliveira \\ Instituto Federal de Educação, Ciência e Tecnologia do Ceará \\ (IFCE - Campus Sobral, Grupo de Pesquisa em Física Aplicada e Docência) \\ (profantuness@gmail.com)
}

Paulo Alberto Avelino Andrade

Instituto Federal de Educação, Ciência e Tecnologia do Ceará (IFCE - Campus Sobral)

(pauloalberto21@hotmail.com)

Marcos Cirineu Aguiar Siqueira

Instituto Federal de Educação, ciência e Tecnologia do Ceará (IFCE - Campus Maracanaú, Grupo de Pesquisa em Física Aplicada e Docência)

(mcirineu@gmail.com)

\begin{abstract}
Resumo: Motivar os alunos à aprendizagem tem sido uma das grandes preocupações de todos os professores de ciências. Mesmo se existisse nas escolas uma variedade de recursos didáticopedagógicos disponíveis como, por exemplo, laboratório de informática bem equipado, laboratório de Física estruturado para todos os conteúdos, biblioteca atualizada, bem como monitores plantonistas, ainda sim, motivar os alunos nas aulas continuaria sendo um obstáculo a ser superado, pois esta é uma dificuldade excepcionalmente ampla. O presente trabalho foi realizado mediante uma pesquisa de campo subsidiada por um estudo bibliográfico, visando investigar fatores e estratégias capazes de interferir na motivação dos alunos durante as aulas de Física. A pesquisa de campo foi concretizada no segundo semestre de 2017, numa escola de ensino médio pertencente à rede pública de ensino na região norte do Ceará e envolveu a aplicação de um questionário com 5 (cinco) perguntas destinadas a 60 (sessenta) discentes do ensino médio, entre 14 e 35 anos de idade. Os resultados revelam alguns obstáculos notáveis envolvidos no ensino de Física e colocam em destaque o ensino noturno, onde o percentual de alunos que se julgam motivados ao estudo da disciplina é bem menor do que no período matutino. Diante deste fato, é pertinente entender a problemática subjacente e apontar possibilidades para a superação do problema.
\end{abstract}

Palavras-chave: Ensino de Física; Motivação; Aprendizagem.

\section{The motivation in classroom: what do students say about High School Physics classes?}

Abstract: Students' motivation in physics classes has been a major concern of all science teachers. Even if there were a variety of didactic and pedagogical resources available, such as a well-equipped computer lab, a structured physics laboratory for all contents, an updated library, as well as teacher's assistants to clarify the doubts of the students, even so motivate students during the classes would continue to be an obstacle to be overcome, as this is an exceptionally broad difficulty. This work was carried out through a field research subsidized by a bibliographic study to investigate the motivation factor with high school students during the physics classes. The field research was accomplished in a public high school in the northern region of Ceará and involved the application of a questionnaire containing 5 (five) questions applied to 60 (sixty) students from high school, between 14 (fourteen) and 35 (thirty-five) years of age. The results reveal some notable obstacles involved in physics teaching and highlight the nocturnal teaching, where the percentage of students who consider themselves motivated to study the discipline is much lower than in the morning period. Facing this fact, it is pertinent to understand the underlying problems and to point out possibilities for overcoming the problem.

Keywords: physics teaching; motivation; learning. 


\section{INTRODUÇÃO}

A sociedade tem passado por mudanças profundas desde o século passado e a escola precisa considerá-las em todo seu contexto a fim de oferecer uma formação ampla, sólida e condizente com as atuais necessidades dos cidadãos. Diante disso, Raasch (1999) enfatiza o desafio do educador para coordenar o ensino de conceitos e proporcionar um ambiente efetivo de aprendizagem:

O final do século XX e início do XXI caracterizou-se por grandes
mudanças, em praticamente todos os setores da vida humana, essas
transformações são fatos marcantes, dentre os quais destacam-se: a
globalização dos mercados, o desgaste dos valores e tradições
nacionais em prol da crescente ambição monopolista de países ditos
desenvolvidos. Podemos acrescentar ainda o individualismo e o
ufanismo que prevalecem sobre a solidariedade. Em meio a essa
diversidade de inovações, não podemos desconsiderar a educação,
pois a mesma, não deve estar à margem, mas inserida no processo e
se adequando às novas necessidades de sua clientela. Essas
questões são reais, e como tais, devem ser questionadas e
analisadas. (RAASCH, 1999, p.1)

Para Raasch (1999), os educadores têm enfrentado historicamente o problema da ausência de motivação dos alunos durante o processo de ensino-aprendizagem e, por conseguinte, o quesito organização da sala de aula se revelou particularmente relevante. Por isso mesmo, uma vez que estejam inseridos nesse contexto, os facilitadores do processo precisam ter conhecimento de estratégias motivacionais que favoreçam a concretização de uma aprendizagem significativa e, nesse sentido, uma das estratégias que merecem realce refere-se ao uso criterioso da linguagem durante a exposição didática.

De acordo com Ausubel (2003) a aprendizagem significativa se dá a partir de ancoragem dos conceitos recém-descobertos aos conceitos interiores pré-existentes na estrutura cognitiva do aluno, os subsunçores. Ao contrário da aprendizagem mecânica, que se dá de forma arbitrária, literal e volátil, a aprendizagem significativa se dá de forma não arbitrária, não literal e tende a se perpetuar na memória do aprendiz, daí o seu caráter referencial.

Outras estratégias são postuladas por Engelmann (2010). Para ele, atividades que representem novidades (N), desafios (D) e valores (V) são capazes de gerar Motivação Intrínseca, além disso, os alunos que conseguem maior apoio à autonomia 
(A) por parte dos professores demonstram interesse pelo estudo e gastam mais o seu tempo livre na realização das tarefas escolares.

Segundo Guimarães (2004), a Motivação Intrínseca:

É o fenômeno que melhor representa o potencial positivo da natureza humana(...) configura-se como uma tendência natural para buscar novidades, um desafio para obter e exercitar as próprias capacidades. Refere-se ao envolvimento em determinada atividade por sua própria causa, por esta ser interessante, envolvente ou de alguma forma, geradora de satisfação. (GUIMARÃES, 2004, p.143)

Neste contexto, cabe então ao professor a responsabilidade de planejar suas aulas com ações atrativas aos educandos, capazes de promover o seu interesse e comprometimento por meio de atividades desafiadoras que proporcionem novos conhecimentos e habilidades. Ações que explorem atividades do tipo (N), (D), (V) e (A) têm o potencial de promover a Motivação Intrínseca e suscitar um comportamento autônomo e autodeterminado nos alunos.

A motivação no contexto escolar tem sido avaliada como um determinante crítico do nível e da qualidade da aprendizagem e do desempenho. Um estudante motivado mostra-se ativamente envolvido no processo de aprendizagem, engajando-se e persistindo em tarefas desafiadoras, despendendo esforços, usando estratégias adequadas, buscando desenvolver novas habilidades de compreensão e de domínio. Apresenta entusiasmo na execução das tarefas e orgulho acerca dos resultados de seus desempenhos, podendo superar previsões baseadas em suas habilidades ou conhecimentos prévios. (GUIMARÃES, 2004, p.143)

Buscando superar as adversidades enfrentadas pelo professor em sala de aula é que se tem intensificado a pesquisa em ensino de Física. Com ela, surgiram comprovações da necessidade, importância e eficácia da utilização de algumas estratégias capazes de motivar o aluno ao estudo do mundo físico. Entre elas, citese:

a) A utilização da Física do cotidiano;

Esta estratégia leva em conta o fato de que o aluno valoriza algo, isto é, motivase intrinsecamente, quando percebe sua utilidade, quando há uma aproximação entre o conhecimento do mundo físico e a realidade vivenciada, de forma que ele dê significado ao que aprende e consiga fazer uso frequente do conhecimento adquirido, 
sabendo vinculá-lo aos fenômenos que presencia nas suas interações em sociedade. Segundo Zen e Pereira (2013):

O cenário atual para o ensino de Física é de muitas dificuldades, principalmente com relação às dificuldades de aprendizagem nas aulas de Física e a prática pedagógica do professor. Um fator que pode ajudar em ambas as dificuldades é a contextualização do conteúdo, aproximando os conceitos físicos abordados em sala de aula com o cotidiano dos alunos. O professor, ao incorporar uma prática pedagógica que contemple essa contextualização pode conseguir resgatar o interesse dos alunos pela Física assim como também ajudar na aprendizagem deles. (ZEN; PEREIRA, 2013, p.3)

Nesse sentido, faz-se necessário que o professor observe os parâmetros regionais que cercam as escolas e as condições de seus educandos com relação a seu contexto de vida e demais especificidades. Somente dessa forma ele conseguirá elaborar atividades que proporcionem maior interação entre o conhecimento exposto ao aluno e seu cotidiano. É preciso buscar formas de ensinar ciências em que não se perpetue a violência cultural, mas que se respeite a visão de mundo das comunidades, seus valores, linguagem, sentimentos, ações e desejos. Uma escola democrática e motivadora deve considerar os conhecimentos científicos aplicados localmente, dentro do contexto em que o aluno está inserido.

b) Atividades experimentais no ensino de ciências;

É fato comprovado por pesquisas da área, a exemplo da desenvolvida por Júnior e Silva (2013), que as atividades experimentais contribuem com o desenvolvimento das formas de percepção qualitativa e quantitativa dos estudantes à medida que os motivam através de sua curiosidade. Para além disso, a possibilidade de propor hipóteses e de verificá-las ou refutá-las diretamente suscita neles proatividade e autonomia de pensamento. Para Morais e Junior (2014):

A abordagem da ciência por meio de experimentos didáticos tem uma grande importância na aprendizagem dos estudantes, pois é, na prática, motivados por sua curiosidade, que os alunos buscam novas descobertas, questionam sobre diversos assuntos e, o mais importante, favorece uma aprendizagem mais significativa. Tendo em vista que nos experimentos os conhecimentos prévios dos alunos, sendo levados em consideração, podem auxiliá-los bastante para a apreensão de novos conhecimentos. E isso sendo feito de forma prática, é algo que atrai geralmente os alunos. (MORAIS; JUNIOR, 2014, p. 62) 
Para Axt e Moreira (1991):

[...] o quadro atual diverge, então, muito pouco do passado: embora se reconheça a importância das atividades experimentais e um significativo número de professores já as pratique, a proporção, em relação aos que se limitam ao giz e quadro negro, ainda é pequena. Além disso, raramente a experimentação é explorada em toda a sua potencialidade. (AXT; MOREIRA, 1991, p. 98)

Desde que Axt e Moreira escreveram esse artigo em 1991 muita coisa mudou na educação: os quadros negros estão à beira da extinção nas escolas, o acesso a novas tecnologias foi facilitado, escolas ganharam laboratório e equipamentos para práticas experimentais, laboratórios de informática para pesquisas e práticas de experimentos virtuais, etc., entretanto a experimentação ainda não ganhou o espaço adequado nas escolas de ensino médio.

De acordo com Moraes (2000), um experimento representa "um ensaio científico destinado à verificação de um fenômeno físico. Portanto, experimentar implica pôr à prova; ensaiar; testar algo." Segundo ele, as atividades práticas, incluindo a experimentação, desempenham um papel fundamental no ensino de Ciências por possibilitarem ao aluno uma aproximação com a expressão concreta do conhecimento científico natural e podem ser, inclusive, desenvolvidas dentro de diferentes concepções filosófico-metodológicas. Japiassú e Marcondes (1996), ao definirem a palavra experimentação, enfatizam que ela busca verificar uma hipótese oriunda da experiência, fato este que empresta a ela importante papel dentro da didática aplicada ao ensino da Física.

A fim de potencializar as atividades experimentais para que estas colaborem com a efetivação do aprendizado e a inclusão dos envolvidos, propiciando seu maior engajamento, de forma que os experimentos resultem em conclusões próprias dos estudantes, mediante análise de hipóteses e investigações práticas, cabe ao professor mediar o processo de aprendizagem colocando os alunos para pensar, interagir e descobrir os principais resultados científicos que podem ser compreendidos a partir da aquisição dos conhecimentos contemplados no currículo de sua escola.

c) Vinculação entre o conhecimento científico, as tecnologias e a sociedade (CTS); 
A percepção, por parte do aluno, da importância que o conhecimento científico apresenta na produção de novas tecnologias e da grande influência que estas últimas têm sobre o contexto social e cultural ao seu redor, pode representar fator potencializador do seu interesse pela Ciência, desde que a abordagem escolhida de fato enfatize as questões cruciais para a formação do aluno, conforme destaca Santos (2007). De um modo geral, esse tipo de paradigma, por incluir abordagens contextualizadas, favorece discussões interdisciplinares:

A perspectiva CTS trata do trabalho com questões ligadas à ciência $e$ à tecnologia, que possuem impactos sociais (econômicos, políticos) e ambientais, de forma crítica, relacionando o conhecimento científico com o tecnológico, e mostrando as relações dos mesmos com a sociedade. Numa proposta de ensino na perspectiva CTS, aulas sobre a Física Nuclear, por exemplo, teriam como finalidade não só ensinar os conteúdos como fissão e fusão nuclear ou decaimento radioativo aos alunos, mas também relacioná-los com o campo da tecnologia, na produção de energia elétrica, nas aplicações na indústria, medicina, agricultura, os impactos ambientais que seu uso causa, os riscos biológicos, os acidentes nucleares já ocorridos e os interesses políticoeconômicos por trás de seus usos, sempre buscando fazer com que o aluno não só conheça o conteúdo, mas que também seja capaz de posicionar-se sobre o assunto e tenha conhecimento básico para tomada de decisões. (SANTOS; ANDRADE, 2013, p.2)

$\mathrm{Na}$ medida em que promove o interesse dos estudantes relacionando os temas ciência, tecnologia e sociedade, o professor é capaz de inserir, nas discussões de sala de aula, assuntos que envolvem as implicações sociais e éticas da ciência e da tecnologia. Esse tipo de abordagem é essencial para formar cidadãos conscientes e aptos a se manifestarem diante de uma sociedade cada vez mais capitalista, tecnológica e industrializada.

d) O modelamento matemático;

Para Souza e Santo (2010, p.1), "o processo de modelagem matemática gera um ambiente que pode favorecer o aprendizado não apenas de Matemática, mas de outras disciplinas como a Física, a Química e até mesmo a Biologia". A introdução da modelagem matemática pode facilitar a construção de relações e significados de modo a favorecer a aprendizagem construtivista, podendo: (a) elevar o nível do processo cognitivo, exigindo que os estudantes pensem num nível mais elevado, generalizando conceitos e relações; (b) exigir que os estudantes definam suas ideias mais precisamente; (c) propiciar oportunidades para que os estudantes testem seus 
próprios modelos cognitivos, detectem e corrijam inconsistências. Por outro lado, segundo Pietrocola (2002, p. 90), "no ensino da Física, a linguagem matemática é muitas vezes considerada como a grande responsável pelo fracasso escolar".

e) Aproximação entre a história da ciência e o ensino de ciências;

Para Martins (2006) apud Erthal e Linhares (2009, p. 2), "há alguns anos que educadores de todo o mundo, inclusive do Brasil, têm reconhecido o potencial de utilização da história da ciência no ensino de todos os níveis". Embora a história da ciência não ofereça respostas para a crise pela qual vem passando o ensino de ciências, ela pode contribuir, entre outras coisas, ao: (d) favorecer e fortalecer a compreensão de conceitos e teorias científicas, uma vez que contextualiza a construção do conhecimento; (e) permitir ao aluno uma visão dinâmica da ciência dando oportunidade deles compreenderem-na como uma complexa atividade social, que antecipa e procede ao ato individual da descoberta ou criação; (f) possibilitar uma visão de como as teorias atualmente aceitas evoluíram em consequência de uma atividade humana e coletiva; (g) mostrar a ciência como algo em construção e combater o dogmatismo, aspecto desenvolvido em determinados contextos sociais;

\section{METODOLOGIA}

A opção pela temática "motivação em sala de aula" se deu em decorrência da experiência vivenciada por um dos autores durante a disciplina de estágio supervisionado III, cursada em um dos campi do Instituto Federal de Educação, Ciência e Tecnologia do Ceará (IFCE). Percebeu-se que um dos principais obstáculos encontrados pelo professor na condução do processo de ensino-aprendizagem estava ligado ao engajamento dos discentes nesse processo. Diante disso, o presente trabalho tomou como principal objetivo averiguar quais as principais impressões dos alunos a respeito das aulas e como estas poderiam se tornar mais atrativas.

O universo que constituiu a investigação foi composto por pesquisas que dizem respeito ao ensino de Física e à motivação da aprendizagem, além de um grupo de 60 estudantes, alunos do $1^{\circ}, 2^{\circ}$ e $3^{\circ}$ anos do ensino médio numa escola de ensino pertencente à rede pública de ensino na região norte do Ceará. Os discentes foram selecionados mediante o seguinte critério: cursar uma das três séries do ensino médio 
nos turnos manhã ou noite. Tal escolha deve-se ao fato de se querer confrontar dados dos dois turnos uma vez que existem diferenças perceptíveis entre os alunos que cursam no turno manhã e o turno noite e, entre elas, pode-se destacar: a idade e a ocupação (trabalho).

Ao escolher-se uma abordagem investigativa para o referente trabalho, optou-se pela pesquisa de cunho qualitativo, levando em consideração algumas características citadas pelos autores Ludke e André (2017), dentre as quais se destaca o fato de a fonte direta de dados ser obtida em um ambiente natural e ter o pesquisador como seu principal instrumento de pesquisa.

Conforme afirmam Bogdan e Biklen (1994):

Os investigadores qualitativos frequentam os locais de estudo porque se preocupam com o contexto. Entendem que as ações podem ser melhor compreendidas quando são observadas no seu ambiente habitual de ocorrência. (BOGDAN; BIKLEN, 1994, p. 48)

A pesquisa ocorreu após o período de observação de aulas na disciplina de estágio supervisionado III e, para sua aplicação, foi solicitada autorização da escola, mediante assinatura de um termo de consentimento do qual foram produzidas duas cópias, uma sendo deixada na secretaria da escola e outra arquivada pelo (a) professor (a) da disciplina.

A pesquisa com alunos foi concretizada mediante a aplicação de um questionário contendo 5 (cinco) questões, nas quais buscou-se sondar se eles gostavam das aulas de Física, como eles imaginavam que seria uma aula atraente e motivadora, se fatores familiares, amizades e o trabalho estavam influenciando em seu rendimento em sala de aula, como era sua relação com o professor da disciplina e se o docente tinha conseguido, até então, motivá-los nas atividades propostas.

O questionário foi elaborado e aplicado conforme os critérios propostos por Günter (2003), tendo em vista uma redução de custos e oportunização de feedback para os respondentes, primando-se pela brevidade e comunicabilidade do texto, e pela assertividade do instrumento. Utilizou-se uma escala nominal compatível com os interesses da pesquisa.

A aplicação do questionário foi feita somente com aqueles alunos que se voluntariaram a respondê-lo (10 alunos/turma), não sendo, portanto, aplicado a toda 
a turma. Em vista da homogeneidade social, condições socio-afetivas e intelectuais serem bastante semelhantes, não há razão para considerar discrepâncias significativas entre suas respostas, como de fato foi possível ver através das análises do questionário.

Dos alunos que responderam ao instrumento, 30 eram do turno da manhã, sendo eles divididos igualmente entre a primeira, segunda e terceira séries e 30 das turmas noturnas, distribuídos da mesma forma.

Para a análise dos dados procurou-se estabelecer uma comparação entre as respostas dadas às perguntas e as teorias associadas aos respectivos marcos teóricos adotados. Os alunos que responderam aos questionamentos estavam na faixa etária entre 14 e 35 anos. Utilizou-se uma amostragem por conveniência, partindo do pressuposto de que, no contexto estudado, não há características fundamentais que diferenciem os sujeitos consultados do restante da população em questão, o que permite a uma pesquisa de baixo custo apreender tendências reais de amplo espectro dentro do universo estudantil. Nesse sentido, e tendo em vista o forte teor subjetivo das respostas, optou-se por desconsiderar níveis de confiança e margens de erro bem como a possibilidade do uso de testes paramétricos dentro do trabalho. A análise dos dados coletados através da aplicação dos questionários foi realizada a partir da tabulação das informações fornecidas por esses sujeitos. No tratamento quantitativo dos dados, foram utilizadas técnicas básicas de estatística, tais como o cálculo de porcentagem e, para tabulação dos questionários e construção dos gráficos, utilizou-se o programa editor de planilhas Excel, da Microsoft, ano 2007.

\section{RESULTADOS E DISCUSSÕES}

A seguir são apresentados e discutidos os resultados obtidos através da aplicação de questionários direcionados aos alunos da escola em questão. Para identificar os alunos será usada uma letra minúscula e, para diferenciá-los, um número indicativo do ano que ele cursa seguido de uma letra maiúscula que designa seu turno. Exemplos: a1M para designar o aluno a do primeiro ano Manhã, c2N para indicar o aluno $\mathrm{c}$ do segundo ano Noite, f3M para o aluno f do terceiro ano manhã, etc. 


\section{Análise e discussão das respostas à primeira pergunta do questionário}

A primeira pergunta do questionário foi direcionada no sentido de saber deles sobre suas afinidades com a área (Você gosta das aulas de Física?). No quadro $1 \mathrm{a}$ seguir, destacamos os principais pontos pautados pelos alunos para justificar seu gosto, ou então descontentamento com as aulas e com a disciplina. As principais respostas foram enquadradas em quatro categorias independentes entre si, que procuraram privilegiar a percepção de cada sujeito consultado. Essa categorização dos dados, para todas as perguntas, foi feita por diferenciação e reagrupamento, como preceitua Bardin (2007), e obedecendo a critérios semânticos. Ela foi realizada em duas etapas: o inventário, no qual foram isoladas as falas, e a classificação, quando foram reunidas em grupos. Segue a síntese para a primeira pergunta:

Quadro 1: Categorização das respostas dos alunos à primeira pergunta do questionário.

\begin{tabular}{|c|c|}
\hline CATEGORIA & PRINCIPAIS RESPOSTAS DOS ALUNOS \\
\hline $\begin{array}{l}\text { PRESENÇA DA MATEMÁTICA } \\
\text { NAS AULAS DE FÍSICA }\end{array}$ & $\begin{array}{l}\text { b1M: Sim, porque sempre gostei de Matemática; } \\
\text { b3M: Sim, apesar de ter muitos cálculos, mas eu gosto; } \\
\text { e2N: Não. Nunca aprendi Matemática, e nem Física; } \\
\text { h2N: Não sei Matemática, e preciso dela na Física e isso me } \\
\text { atrapalha, e por isso não gosto; }\end{array}$ \\
\hline $\begin{array}{c}\text { METODOLOGIA UTILIZADA } \\
\text { PELO PROFESSOR NA } \\
\text { ABORDAGEM DOS CONTEÚDOS }\end{array}$ & $\begin{array}{l}\text { d3M: Sim, mas gosto mais quando o professor conta as } \\
\text { histórias dos físicos, não gosto dos cálculos; } \\
\text { i2N: Sim, antes eu não gostava, achava chata, sem graça, } \\
\text { mais esse ano está interessante, e vejo que ela é muito } \\
\text { importante na nossa vida; } \\
\text { e3N: Sim, antes eu não gostava mais depois que o professor } \\
\text { levou a gente para o laboratório eu acho massa; } \\
\text { h3N: Não, o professor não sabe explicar, já não é uma } \\
\text { disciplina fácil e ainda com um cara que não sabe explicar } \\
\text { deixa as coisas mais difícil ainda; } \\
\text { i3N: Não. O professor só fala de Enem direto, toda aula é } \\
\text { Enem, ele parece que só sabe ensinar Enem; }\end{array}$ \\
\hline $\begin{array}{c}\text { A TRANSPARÊNCIA DO } \\
\text { DOMÍNIO DE CONTEÚDO DO } \\
\text { PROFESSOR }\end{array}$ & $\begin{array}{l}\text { b3N: Não. Só cálculos, só contas, o professor se acha e a } \\
\text { gente ver que ele se enrola todinho; }\end{array}$ \\
\hline $\begin{array}{l}\text { AVALIAÇÃO DA } \\
\text { APRENDIZAGEM }\end{array}$ & $\begin{array}{l}\text { g3M: Não, detesto, nunca aprendi e nem vou aprender; } \\
\text { a3N: Cada ano que passa ela fica mais difícil; }\end{array}$ \\
\hline
\end{tabular}

Fonte: Crédito dos autores.

Observando o quadro 1 podemos perceber que:

- A presença da Matemática nas aulas de Física foi apontada pelos alunos tanto como justificativa para gostar das aulas quanto para o seu descontentamento com elas. Como a Matemática é uma ferramenta essencial para o modelamento, análise e compreensão de dados experimentais, a sua não compreensão pode comprometer 0 
entendimento e motivação dos alunos durante as aulas de Física, bem como o próprio gosto pela matéria, ao passo que a afinidade com ela pode contribuir substancialmente na aprendizagem dos conteúdos ministrados, conforme constatado por Souza e Santo (2010).

- Nas respostas dos alunos, há pontos que confirmam a importância da história das ciências e dos cientistas como estratégia para motivar estudantes à aprendizagem de Física, o que confirma a fala de Martins (2006) apud Erthal e Linhares (2009). Além disso, observamos que os alunos valorizam abordagens contextualizadas que enfatizam a Física vivenciada por eles como defende Zen e Pereira (2013).

- O fato de o professor não transparecer domínio da matéria ensinada compromete o gosto dos alunos por ela, uma vez que eles acabam por desvalorizar a aula. Investigando posteriormente a formação dos quatro professores que lecionavam para os alunos em foco, constatou-se que apenas um tinha formação na área, sendo assim é natural eles não terem o domínio suficiente dos conteúdos e metodologias para fazer uma exposição clara, uma vez que essa formação geralmente é obtida no ambiente universitário, cursando disciplinas específicas.

- Se o conteúdo não é compreendido pelo aluno, ele fica desmotivado e sem ânimo para prestar atenção nas aulas, pois à medida que o professor segue na abordagem dos conteúdos, as suas dificuldades aumentam, uma vez que conteúdos anteriores geralmente são pré-requisitos para os seguintes. Nesse caso, os tópicos frasais relacionados aos conceitos fundamentais do conteúdo ministrado poderiam ser utilizados pelo professor para fazer com que o aluno aprendesse significativamente, isto é, o melhor ponto de partida para a explanação corresponde aos conceitos já presentes na estrutura cognitiva do aluno (subsunçores), a partir dos quais se pode agregar novos conceitos e definições com eficácia. Neste ponto, destaca-se a importância da adoção de uma prática avaliativa contínua por parte do professor, pois, uma vez que ele detecte que determinados alunos não estão compreendendo o conteúdo exposto, poderá buscar novas estratégias ou metodologias que ajudem a superar esse obstáculo, que ao ocorrer repetidas vezes, pode gerar no aluno um "bloqueio" à matéria, como podemos perceber nas falas do g3M e do a3N.

Estas falas refletem as respostas à primeira pergunta do questionário quando aplicada aos 60 alunos envolvidos na pesquisa. Na Figura 1 pode-se visualizá-las mediante o gráfico de colunas com as respectivas porcentagens. 
Figura 1: Respostas dos alunos à primeira pergunta.

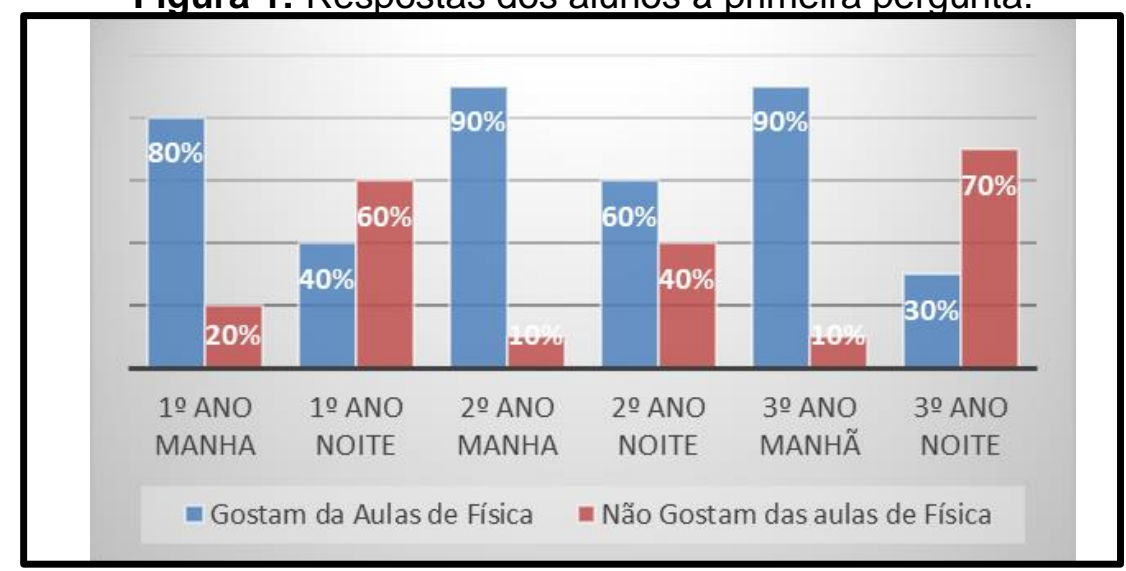

Fonte: Créditos dos autores.

É possível observar na Figura 1 que os alunos do turno manhã têm mais afinidade com as aulas de Física do que os do turno noite e que essa diferença é surpreendente, uma vez que o número de alunos motivados se reduz drasticamente no turno noite do primeiro ao terceiro ano, enquanto que no turno manhã ocorre um aumento do primeiro para o segundo ano e o percentual permanece estagnado do segundo para o terceiro ano. Observa-se uma regularidade no comportamento dos números referentes as turmas da manhã em contraste com o comportamento aparentemente instável dos números das turmas da noite, fato que sugere a proeminência de variáveis não controladas dentro do contexto noturno. Buscando justificativas para o fato, chegamos às seguintes proposições:

i) Os alunos matriculados no turno da noite geralmente trabalham, tendo pouco tempo para dedicar-se aos estudos e acabam se desmotivando mais facilmente ao estudo das ciências, que geralmente são ensinadas com enfoque nos cálculos. Para Carvalho (2001), o cerne do problema de ensino-aprendizagem noturno é a relação escola-trabalho;

ii) Os professores que ministram aulas no turno noite chegam bem mais fadigados e suas aulas acabam sendo menos atrativas (a maioria dos professores da noite também ministram aulas de manhã e à tarde);

iii) O aluno do ensino médio noturno geralmente ingressa com maior número de reprovações, e com isso, nesta etapa encontra-se desmotivado ao estudo de disciplinas da área de ciências, com a noção de que é tudo muito difícil; 
iv) As aulas no turno da manhã têm duração de 50 minutos ao passo que no turno da noite têm duração de 45 minutos e uma aula a menos. Isso afeta o andamento das aulas e prejudica os desempenhos docente e discente no médio-longo prazo;

v) As aulas noturnas estão envolvidas em uma série de problemas, entre elas a violência e uso de drogas que, por vezes, viram rotina até mesmo no ambiente escolar, prejudicando o processo de ensino-aprendizagem.

Com relação às aulas noturnas:

Nota-se a existência de uma quase impossibilidade de enfrentar as aulas à noite. $O$ trabalho solicita muito dos alunos, e eles não encontram na escola "o mundo de sabedoria" que esperavam. Ao contrário, identificam quase uma hostilidade inerente à vida escolar, que exige ficar à disposição dos professores "que falam sem parar". (CARVALHO, 2001, p. 61)

$\mathrm{Na}$ fala de Carvalho (2001), nota-se a importância de um ensino que esteja voltado ao aluno de forma que este seja um protagonista mais ativo na construção do seu próprio conhecimento, um processo educativo em que o professor atue mais como mediador do que como detentor do conhecimento, onde os conhecimentos prévios, interesses e necessidades dos discentes sejam levados em consideração. Como é possível perceber através da leitura de Carvalho (2001), a ausência de protagonismo dos estudantes e o seu cansaço é, na maioria das vezes, a causa para que os mesmos se desliguem das aulas e até mesmo cochilem durante a exposição do professor, o qual geralmente segue um cronograma rígido e com pouquíssimo tempo para cumprilo.

\section{Análise e discussão das respostas à segunda pergunta do questionário}

A segunda questão procurou saber dos discentes suas expectativas para as aulas de Física de forma que estas se tornassem mais atrativas (Para você, como seria uma boa aula de Física?). A partir de uma interpretação metódica das respostas produziu-se o quadro 2, o qual expressa a opinião dos alunos sobre as principais estratégias que poderiam ser adotadas pelo professor. 
Quadro 2: Estratégias que poderiam ser adotadas pelos docentes para aulas mais atraentes e motivadoras.

\section{ESTRATÉGIAS DIDÁTICAS}

- Ênfase maior nas interpretações dos fenômenos do que na Matemática envolvida no seu modelamento;

- Ao resolver exercícios, pensar mais nos princípios físicos envolvidos do que na utilização direta de algumas fórmulas;

- Práticas experimentais e utilização mais frequente dos laboratórios;

- Dedicar maior tempo às explicações e compreender as deficiências de aprendizagem dos alunos, nas palavras deles: "ter paciência com a gente";

- Aulas dinâmicas e participativas;

- Estimular a aprendizagem dos conteúdos através de suas aplicações no cotidiano;

- Aulas de campo;

- Aulas mediadas pelo uso de Datashow e TVs, com a exposição de figuras, vídeos, filmes, etc.;

- Trabalhar melhor a relação professor-aluno;

- Dar oportunidade para os alunos fazerem experimentos com materiais de baixo custo e expor em sala de aula para os colegas.

Fonte: Crédito dos autores.

É importante considerar aqui as indicativas dos alunos, pois estas podem contribuir para que o professor diversifique suas metodologias atendendo às diferentes demandas do ambiente escolar, como alertam Sanmarti (2002) e Bueno (2003) apud Viveiro e Diniz (2009). Para esses autores o pluralismo de estratégias possibilita oportunidades para construção do conhecimento e oferece meios para que mais estudantes compreendam o tema abordado.

\section{Análise e discussão das respostas à terceira pergunta do questionário}

A terceira pergunta objetivava saber de cada estudante se o seu relacionamento com familiares, amigos, ou o seu trabalho, interferiam na aprendizagem em sala de aula e de que forma ( $\mathrm{O}$ seu relacionamento com seus pais, familiares, amigos ou o seu trabalho interferem no seu comportamento e na sua aprendizagem em sala de aula?).

Analisando as respostas dos alunos a essa pergunta verificou-se que $85 \%$ dos participantes da coleta de dados veem o relacionamento deles com seus familiares, amigos e o trabalho, como fatores capazes de interferir no seu desempenho em sala de aula. Percebe-se aqui a presença de outras condições afetivas além daquelas associadas à relação professor-aluno, que interferem diretamente na motivação do aluno ao estudo e que, consequentemente, apresentam-se como obstáculos à aprendizagem. $O$ foco dessa pergunta era saber dos alunos quais influências eles 
sofriam dentro ou fora da escola e que impactavam negativamente no seu aprendizado.

Segundo o relato do aluno b1M: "quando um começa a bagunça os outros continuam", o que nos leva a inferir que alunos desmotivados, ao participarem das aulas, acabam influenciando negativamente os outros alunos no sentido de provocar desvios de conduta que comprometem a sua aprendizagem. Já o aluno i1M, afirma que, incentivado por outros alunos, às vezes ele "gazeia" aula para jogar vídeo game. É natural do ser humano buscar ações que lhe despertem prazer, assim como o jogo e as rodas de conversa. Nesse sentido, as atividades desenvolvidas em sala de aula precisam ser capazes de prender a atenção dos envolvidos e possibilitar que eles estejam ali por vontade própria, não por obrigação. Para os entrevistados a relação afetiva com seus familiares e outros fatores ligados ao trabalho também conseguem tirar deles o foco dos estudos.

Dentro deste contexto, o professor enquanto mediador do processo de ensinoaprendizagem tem uma grande responsabilidade, que vai além do conhecer o conteúdo a ser ensinado. Uma vez que o aluno chega à sala de aula com defasagem em conteúdos e em condições emocionais desfavoráveis à realização das tarefas escolares, se o professor não souber preparar sabiamente as atividades de aula, além de conduzir com maestria o contexto relacional, certamente ele não conseguirá resgatar a motivação de seu aluno e levá-lo a concentrar-se na atividade educativa, haja vista que apenas $15 \%$ dos alunos da pesquisa mostram foco nos estudos.

\section{Análise e discussão das respostas à quarta pergunta do questionário}

A quarta pergunta buscava averiguar como era a relação professor-aluno e que características do professor de Física poderiam colaborar com a presença de alunos motivados em sala de aula (Você gosta do seu professor de Física? Por quê?).

Das seis turmas que participaram da pesquisa, apenas as do $2^{\circ}$ ano manhã e $3^{\circ}$ ano manhã aprovaram, de forma absoluta, o professor da disciplina, os demais resultados mostram dados preocupantes: $40 \%$ dos alunos do $1^{\circ}$ ano manhã, $70 \%$ do $1^{\circ}$ ano noite, $20 \%$ do $2^{\circ}$ ano noite, e $60 \%$ do $3^{\circ}$ ano noite, não aprovam o professor da disciplina. Ao verificar a formação dos professores, constatamos que somente o professor do $2^{\circ}$ ano noite é licenciado em Física. Esse fato atrelado ao percentual de 
desaprovação, pelos alunos, dos professores não licenciados, coloca em destaque a necessidade de formação de pessoal qualificado atuando em suas respectivas áreas.

Observou-se que um professor de Matemática é que lecionava a disciplina de Física para as turmas dos $1^{\circ}$ anos e $3^{\circ}$ ano noite, já as turmas dos $2^{\circ}$ anos tinham como professor um licenciado em Física e a turma de $3^{\circ}$ ano manhã era conduzida por um professor de Química. A análise de dados mostra, nas aulas de Física, a aceitação dos professores de Física e Química ao passo que o professor de Matemática tem uma rejeição que vai de $40 \%$ da turma no $1^{\circ}$ ano manhã a $70 \%$ no $1^{\circ}$ ํ. ano noite. A pesquisa revela mais uma vez a preocupação com o ensino noturno, uma vez que os alunos desse turno apresentam também maior rejeição ao professor, mesmo o professor licenciado na área obteve rejeição dos alunos noturnos (20\%). No quadro 3, são apresentadas as principais respostas indicadas pelos estudantes para justificar a reprovação do professor.

Quadro 3: Categorização de dados da pesquisa referente à quarta pergunta.

\begin{tabular}{|c|c|}
\hline CATEGORIA & PRINCIPAIS RESPOSTAS DOS ALUNOS \\
\hline $\begin{array}{c}\text { Por causa da metodologia utilizada } \\
\text { pelo professor }\end{array}$ & $\begin{array}{l}\text { j1M: Não, ele só passa contas e contas, e isso faz dele } \\
\text { um chato; } \\
\text { a1N: Não, ele não ensina bem; } \\
\text { i1N: Não, ele não sabe e explicar e ainda culpa a gente } \\
\text { por não entender; } \\
\text { a2N: Não, por que ele passa muitas questões; } \\
\text { g3N: Não, ele deveria ser mais dinâmico, interagir com } \\
\text { os alunos e ele não explica bem o conteúdo e quando } \\
\text { a gente não entende ele culpa a gente. }\end{array}$ \\
\hline $\begin{array}{l}\text { Por causa da postura adotada por ele } \\
\text { em sala de aula }\end{array}$ & $\begin{array}{l}\text { i1M: Não, ele grita muito; } \\
\text { b1N: Não, ele já chamou a gente de burro; } \\
\text { f1N: Não, ele não tem paciência; } \\
\text { e3N: Não, ele já insinuou que os alunos fossem burros, } \\
\text { e acho que o professor jamais pode falar isso para os } \\
\text { alunos; } \\
\text { j3N: Não, a gente ver que ele tem dificuldade mais ele } \\
\text { não desce do salto. }\end{array}$ \\
\hline Por causa da falta de interação & $\begin{array}{l}\text { e1M: Não, ele não conversa com a gente; } \\
\text { i3N: Não, ele deveria ser mais aberto e dialogar com os } \\
\text { alunos, ele só chega e dar aula dele, diferente de outros } \\
\text { professores que conversam com a gente e tiram } \\
\text { brincadeiras, isso torna a aula mais prazerosa. }\end{array}$ \\
\hline
\end{tabular}

Fonte: Crédito dos autores.

Como é possível notar no quadro 3, as maiores reclamações são referentes às metodologias utilizadas pelo professor e sua postura perante a turma. Percebe-se 
claramente nas respostas dos alunos $\mathrm{i} 1 \mathrm{~N}$ e g3N que o professor os responsabiliza pelo não aprendizado.

\section{Análise e discussão das respostas à quinta pergunta do questionário}

A quinta pergunta buscava saber que características apresentadas pelo professor contribuíram com a motivação ou desmotivação dos alunos ao estudo de sua disciplina (O professor te motivou a aprender Física? Justifique.). No quadro 4, a seguir, as respostas foram separadas em duas categorias, desmotivação e motivação, segundo a ênfase dada nas principais falas:

Quadro 4: Categorização de dados da pesquisa referente à quinta pergunta.

\begin{tabular}{|c|c|}
\hline MOTIVAÇÃO & DESMOTIVAÇÃO \\
\hline $\begin{array}{l}\text { - Aulas dialogadas, mediada pelo uso do } \\
\text { quadro, TICs e experimentos; } \\
\text { - Aula centrada nos alunos, com } \\
\text { explicação da Física presente nos } \\
\text { fenômenos de seu dia a dia; } \\
\text { - Professor humanizado, que reconhece } \\
\text { os problemas nos quais estão imersos os } \\
\text { alunos e tenta ajudar, contribui com seu } \\
\text { processo de superação e engajamento } \\
\text { nas atividades; }\end{array}$ & $\begin{array}{l}\text { - A ênfase dada ao tratamento matemático nas } \\
\text { resoluções de questões; } \\
\text { - A ausência de aulas mais criativas com maior } \\
\text { ênfase na experimentação; } \\
\text { - Aulas mediadas exclusivamente pela } \\
\text { utilização do quadro e pincel, sem ilustrações } \\
\text { e experimentação; } \\
\text { - Aula centrada no professor; } \\
\text { - Crítica ao aluno e ausência de motivação } \\
\text { pessoal como incentivo e elogios; } \\
\text { - A mesma mesmice sempre, 'falta de } \\
\text { inovação'. }\end{array}$ \\
\hline
\end{tabular}

Fonte: Créditos do autor.

Os alunos acima parecem aprovar as situações em que o professor se aproximou do grupo para mediar a sua aprendizagem e, inversamente, parecem censurar as situações em que ele se distanciou e resolveu impor o discurso científico, relegando aos alunos o ônus da aprendizagem. Esse fato evidencia claramente a importância das relações subjetivas na construção do conhecimento.

Para Freschi e Freschi (2013), constitui-se num ato de respeito do professor em relação ao aluno considerar os conhecimentos prévios dos mesmos e estimular a participação nas discussões e conversas, o que gera no aluno segurança e confiança no professor e em si mesmo: "a relação professor-aluno precisa ser franca". 


\section{CONCLUSÕES}

Observa-se, na literatura, a indicação do modelamento matemático como aspecto motivador dos conteúdos e, ao mesmo tempo, a pesquisa com alunos indica que se deve ter cautela com tratamentos matemáticos dados aos fenômenos físicos, pois o seu protagonismo tem contribuído para inibir a motivação à aprendizagem nas aulas de Física e são os próprios alunos que alertam para o uso excessivo, dado pelo professor, de questões com ênfase em cálculos. Nesse ínterim, fica implícito que, dentro do contexto escolar estudado nas escolas públicas da região norte do Ceará, as abordagens fenomenológicas da Física têm sido desprivilegiadas e que os alunos egressos do ensino fundamental, de um modo geral, têm tido dificuldades na aplicação dos conhecimentos matemáticos em outras disciplinas.

A literatura enfatiza, ainda, a importância das avaliações de cunho formativo como instrumento pedagógico necessário ao acompanhamento contínuo e processual da realidade de sala de aula além da necessidade de práticas reflexivas por parte do professor, no sentido de conferir ao corpo de alunos o nivelamento suficiente para garantir que ninguém fique 'para trás' durante a exposição formal do conteúdo.

Embora existam indicativos da importância da experimentação no processo de motivação e aprendizagem do aluno, e que eles tenham manifestado interesse por aulas práticas dentro de escolas que dispõem de equipamentos e laboratórios para tais atividades, observa-se nas falas, que os professores não fazem uso frequente de tais possibilidades. Borges (2002) aponta como possíveis justificativas o fato de não existirem atividades já preparadas para o uso do professor, falta de recursos para compra de componentes e materiais de reposição, falta de tempo do professor para planejar a realização de atividades como parte do seu programa de ensino e laboratório fechado e sem manutenção. A solução para este problema passa por ações do governo que incluem o incentivo a qualificação e valorização do professor, a contratação de técnicos especializados para cuidar dos laboratórios e prestar assistência aos docentes durante o planejamento e execução de atividades experimentais, além de investimentos periódicos com materiais e manutenção dos laboratórios. 
A pesquisa constatou uma acentuada influência dos vínculos empregatícios, da conjuntura familiar e da relação professor-aluno na motivação do corpo discente para a apropriação dos conteúdos abordados em sala de aula, bem como a conveniência da utilização de estratégias práticas como aulas de campo e aulas de laboratório para garantir a construção de significados durante o processo de ensino-aprendizagem. A literatura, por sua vez, sugere o uso de conteúdos lúdicos e historiográficos como elementos motivadores no estudo da Física.

Ao analisar as falas dos estudantes para a terceira pergunta, ficou claro que o professor, ao ensinar, concorre com uma diversidade de fatores para motivar seu aluno, o que torna sua atividade ainda mais difícil e exige que o mesmo seja um profissional bem qualificado, com habilidades que vão muito além de saber o conteúdo a ser ensinado.

Tendo em vista, ainda, a maior dificuldade de motivação ao aprendizado dos alunos do turno noite, como constatou a pesquisa, salienta-se a fala de Nery (1999, p. 42) que, ao discorrer sobre o princípio constitucional da igualdade, menciona o fato de que "dar tratamento isonômico às partes significa tratar igualmente os iguais e desigualmente os desiguais, na exata medida de suas desigualdades". Nesse sentido, faz-se mister a implementação de políticas educacionais afirmativas, capazes de mitigar esse desnivelamento, e o ponto de partida é o maior investimento na formação dos professores que ministram aulas à noite, já que os profissionais licenciados são mais bem aceitos pelo corpo estudantil. A concessão de incentivos salariais também se revela importante para que o professor possa priorizar as turmas da noite em seu trabalho diário. O investimento em escolas de tempo integral com bolsas de estudo pode ainda ser um forte elo para combater o trabalho precoce, e a democratização das escolas profissionais também pode ser de muita valia, já que permite uma maior sintonia entre o que o aluno aprende em sala de aula e aquilo que ele realiza diariamente em seu emprego diurno, integrando estudo e trabalho.

Trabalhos futuros poderão fazer um acompanhamento com alunos do nono ano do ensino fundamental até o terceiro ano do ensino médio e verificar o fator motivação para a aprendizagem em Física longitudinalmente, ou seja, ao longo de toda a educação básica. 


\section{REFERÊNCIAS}

AUSUBEL, D. Aquisição e retenção de conhecimentos: Uma perspectiva cognitiva. Plátano Editora: 1. Edição. Janeiro de 2003.

AXT, R.; MOREIRA, M. A. O ensino Experimental e a questão do equipamento de baixo custo. Revista de Ensino de Física, v.13, p. 97-103, 1991.

BARDIN, Laurence. Análise de Conteúdo. Tradução: Luís Antero Reto e Augusto Pinheiro. 4 ed. Lisboa - Portugal. Edições 70, 2007.

BOGDAN, R.; BIKLEN, S. Investigação Qualitativa em Educação: uma introdução à teoria e aos métodos. Porto: Porto Editora, 1994.

BORGES, A. T. Novos rumos para o laboratório escolar de ciências. Caderno Brasileiro de Ensino de Física, v. 19, n.3, p.291-313, dez. 2002.

CARVALHO, C. P de. Ensino Noturno: realidade e ilusão. 10ª Ed - São Paulo, Cortez, 2001. (Coleção Questões da Nossa Época; v.27).

ENGELMANN, E. A motivação de alunos dos cursos de artes de uma Universidade pública do norte do paraná, 2010. Dissertação de Mestrado -Centro de Educação, Comunicação e Artes, Departamento de Educação. Universidade Estadual de Londrina. Londrina, Paraná.

ERTHAL, J. P. C; LINHARES, M. P. História da ciência em sala de aula: o que tem aparecido em nossas revistas? In: Encontro nacional de Pesquisa em Ensino de Ciências, 7, 2009, Florianópolis. Atas do VII Enpec. Belo Horizonte: Associação Brasileira de Pesquisa em Educação em Ciências, 2009. Disponível em: <http://posgrad.fae.ufmg.br/posgrad/viienpec/pdfs/titulos.html>. Acesso em: 25 jul. 2017.

FRESCHI, E. M; FRESCHI, M. Relações Interpessoais: A Construção do Espaço Artesanal no Ambiente Escolar. REI - Revista de Educação do Ideal, v. 8, p. 1, 2013.

GUIMARÃES, S. E. R. O Estilo Motivacional do Professor e a Motivação Intrínseca dos Estudantes: Uma Perspectiva da Teoria da Autodeterminação. Psicologia: Reflexão e Crítica, 2004, 17(2), p.143-150.

GÜNTHER, H. Como Elaborar um Questionário. In: Planejamento de Pesquisa nas Ciências Sociais. v.1 Instituto de Psicologia da Universidade de Brasília, 2003.

JAPIASSÚ H., MARCONDES, D. Dicionário Básico de Filosofia. Rio de Janeiro: Jorge Zahar, 1996.

JUNIOR, E. M. R.; SILVA, O. H. M. Atividades experimentais: uma estratégia para o ensino da física. Cadernos Inter saberes. v. 1, n.2, p. 38-56, 2013.

LUDKE, M.; ANDRÉ, M. E. D. A. Pesquisa em Educação: abordagens qualitativas. 2. ed. Rio de Janeiro: L.T.C, 2017.

MORAES, R., et al. Construtivismo e ensino de ciências: reflexões epistemológicas e metodológicas. 1 ed. Porto Alegre: EDIPUCRS, 2000. 
MORAIS, J. U. P.; JÚNIOR, R, S.S. Experimentos didáticos no ensino de física com foco na aprendizagem significativa. Aprendizagem Significativa em Revista/Meaningful Learning Review. v.4(3), p. 61-67, 2014.

NERY J, Nélson. Princípios do processo civil à luz da Constituição Federal. São Paulo: Editora Revista dos Tribunais, 1999. 42 p.

PIETROCOLA, M. A matemática como estruturante do conhecimento físico. Caderno Catarinense de Ensino de Física, v.19, n.1: p.89-109, ago. 2002.

RAASCH, L. A motivação do aluno para a aprendizagem. Disponível em http://educacaoparavida.yolasite.com/resources/A\%20MOTIVAO\%20DO\%20ALUNO\% 20PARA\%20A\%20APRENDIZAGEM.pdf, consultado em 05-04-2017.

SANTOS, V. H. O.; ANDRADE, C. S. O uso do tema "tecnologia" nas aulas de Física: investigando os discursos dos professores à luz da perspectiva CTS. In: Encontro Nacional de Pesquisa em Educação em Ciências, 9, 2013. Águas de Lindóia, SP. Atas do IX Enpec. Belo Horizonte: Associação Brasileira de Pesquisa em Educação em Ciências, $2009 . \quad$ Disponível em: <http://abrapecnet.org.br/atas_enpec/ixenpec/atas/busca.htm?query=O+uso+do+tema > Acesso em: 25 jul. 2017.

SANTOS, W. L. P. dos. Contextualização no Ensino de Ciências por meio de temas CTS em uma perspectiva crítica. Ciência e Ensino, v. 1, no especial, nov. 2007.

SOUZA, E. S. R.; SANTO, A. O. S. Modelagem Matemática no Ensino de Física: Recursos didáticos-pedagógicos. In: Encontro Paraense de Educação Matemática, 7, 2010. Belém, SP. Atas do VII EPAEM. Sociedade Brasileira de Educação Matemática, 2010.

VIVEIRO, A. A; DINIZ, R. E da SILVA. Atividades de campo no ensino das ciências e na educação ambiental: refletindo sobre as potencialidades desta estratégia na prática escolar. Ciência em Tela, v.1, n.1, 2009.

ZEN, C. R. L.; PEREIRA, R. F. A física do cotidiano: textos paradidáticos de calorimetria e termometria. Os desafios da escola pública paranaense na perspectiva do professor Cadernos PDE, Versão online, vol.1, 2013. Disponível em <http://www.diaadiaeducacao.pr.gov.br/portals/cadernospde/pdebusca/producoes_pde /2013/2013_uem_fis_artigo_claudio_roberto_lopes_zem.pdf>. Acesso em: 3 abr. 2017. 